\title{
Frequency and parental origin of de novo APC mutations in familial adenomatous polyposis
}

\author{
Stefan Aretz*, ${ }^{*}$, Siegfried Uhlhaas ${ }^{1}$, Reiner Caspari ${ }^{2}$, Elisabeth Mangold ${ }^{1}$, \\ Constanze Pagenstecher ${ }^{1}$, Peter Propping ${ }^{1}$ and Waltraut Friedl ${ }^{1}$ \\ ${ }^{1}$ Institute of Human Genetics, University of Bonn, Germany; ${ }^{2}$ Department of Internal Medicine, University of Bonn, \\ Germany
}

A predominance of de novo mutations in the paternal germ line has been reported for several disorders; however, in familial adenomatous polyposis (FAP), the parental origin of APC mutations has been scarcely analysed so far. Among 563 unrelated FAP families with known family history, we identified 58 patients with a suspected de novo mutation in the APC gene. A germline mutation was detected in 52 of them; in 38 patients, the mutation could be excluded in both parents. The five base pair deletion at codon 1309 (c.3927_3931delAAAGA) was over-represented in the group of patients with suspected de novo mutations $(17 / 58=29 \%)$, when compared to the group of familial cases $(26 / 505=5 \%)$; thus, the high frequency of this mutation is not due to a founder effect but rather due to de novo mutation events. Parental origin of de novo mutations could be traced in $\mathbf{1 6}$ families, including three families with large chromosomal deletions. Four mutations were of maternal and 12 of paternal origin, pointing to a moderate preponderance towards paternal origin. Sex-related differences of mutation types could be observed: large deletions and single-base substitutions were exclusively of paternal origin, whereas the small deletions were equally distributed (maternal/paternal ratio 4:4).

European Journal of Human Genetics (2004) 12, 52-58. doi:10.1038/sj.ejhg.5201088

Published online 1 October 2003

Keywords: familial adenomatous polyposis; FAP; APC; parental origin; de novo mutations; 1309

\section{Introduction}

Familial adenomatous polyposis (FAP, MIM *175100) is an autosomal-dominant precancerous condition with a penetrance close to $100 \%$ at the age of 40 , affecting about one in 10000 live births., ${ }^{1,2}$ The disease is characterised by the occurrence of hundreds to thousands of colorectal adenomatous polyps. Some of these benign tumours invariably progress to colorectal cancer, if not surgically removed. In addition, FAP is associated with extracolonic manifestations such as duodenal adenomas, desmoids, osteomas, dental abnormalities and CHRPE. ${ }^{3}$

*Correspondence: Dr S Aretz, Institute of Human Genetics, University of Bonn, Wilhelmstrasse 31, D-53111 Bonn, Germany. Tel: + 49-(0)228-2872391; Fax: + 49-(0)228-287-2380; E-mail: Stefan.Aretz@ukb.uni-bonn.de Received 22 May 2003; revised 1 August 2003; accepted 8 August 2003
Germline mutations in the tumour suppressor gene APC are responsible for FAP. The majority of mutations are distributed over the $5^{\prime}$ half of the APC gene. ${ }^{4-7}$ Germline mutations are almost exclusively nonsense, frameshift or splice site mutations that result in a truncated APC protein. Molecular genetic analysis has revealed a wide variety of private mutations, but some mutational hot spots exist. The most frequent are a 5 base pair (bp) deletion at codon 1309 (c.3927_3931delAAAGA) and a 5 bp deletion at codon 1061 (c.3183_3187 delACAAA). A correlation between site of mutation and clinical phenotype has been observed. Mutations around codon 1309 lead to the most severe intestinal phenotype. ${ }^{8,9}$ However, inter- and intrafamilial variability has been reported as well. ${ }^{7}$

If not inherited, germline mutations causing genetic disorders may occur de novo in oogenesis, spermatogenesis 
or early embryogenesis. Sex- and age-specific patterns in human spontaneous mutations known for several disorders are based at least in part on differences in the processes of oogenesis and spermatogenesis. ${ }^{10,11}$ Studies on the relationship between specific types of de novo mutations and their parental origin may provide further insights into the molecular mechanisms of the genesis of de novo alterations during gametogenesis. Parental origin of $A P C$ mutations in FAP has been systematically examined only once so far. ${ }^{12}$ Here, we present more extensive data on the spectrum of de novo APC mutations in FAP and their parental origin.

\section{Methods Patients}

A total of 917 apparently unrelated patients were examined for germline mutations in the APC gene. Clinical data and family histories were obtained during genetic counselling, clinical management or from medical records. In all, 410 patients had a definite diagnosis of FAP having $>100$ colorectal adenomas, and 171 patients had an attenuated or suspected FAP, with 5-100 adenomas. In the remaining 336 patients, the number of adenomas was not known.

In 563 of the 917 patients, it was possible to discriminate between familial and de novo cases. A de novo mutation was assumed, if there was no family history of FAP and one of the following criteria was fulfilled: (i) Both parents of the patient were healthy until at least 70 years of age. (ii) Both parents had negative colonoscopies at an age $>50$ years. A case was classified as familial, if there was plausible anamnestic evidence for an affected parent or sib or medical records confirming the diagnosis in the relative. The remaining patients included individuals where no information on parents or sibs was available, or where one or both parents died at a younger age from unknown causes.

\section{Mutation analysis}

Genomic DNA was isolated from peripheral blood using standard protocols. ${ }^{13}$ Screening for germline mutations was performed on genomic DNA by either nonradioactive single-strand conformation polymorphism (SSCP) and heteroduplex analysis as described, ${ }^{14}$ or by protein truncation test (PTT) of exon 15 in four overlapping fragments with the in vitro transcription translation kit (Promega, Mannheim, Germany) in the presence of $\left[{ }^{35} \mathrm{~S}\right]$ methionine (Amersham) ${ }^{15}$ and denaturing high-performance liquide chromatography (dHPLC) (WAVE, Transgenomic) for exons 1-14 and the first $500 \mathrm{bp}$ of exon 15 . Polymerase chain reaction fragments showing a variant pattern were sequenced by semiautomated cycle sequencing with BigDye chain terminators on an ABI 377 sequencer (Applied Biosystems, Weiterstadt, Germany). In patients with suspected large deletions including region $5 \mathrm{q} 22$, conventional chromosome analysis was performed using standard protocols.

\section{Haplotype analysis}

The parental origin of de novo mutations was traced by haplotype analysis in three-generation families (pedigrees 1-13) or two-generation families (pedigrees 14-16) using an intragenic polymorphism (SNP at codon 1960 of the $A P C$ gene) and microsatellite markers flanking the APC region (the order of markers on chromosome $5 \mathrm{q}$ is: CEN D5S299 - D5S82 - D5S134 - APC - D5S346 - MCC D5S2001 - D5S1385 - D5S138, the markers are spanning $14 \mathrm{cM}$; see http://www.genome.ucsc.edu/). Paternity testing was performed by use of at least six highly polymorphic microsatellite markers from the chromosomal regions 5q22 and/or 17p11.2.

\section{Results}

Detection of APC mutations

Between 1990 and 2002, we examined 917 apparently unrelated FAP patients for germline mutations in the APC gene. A pathogenic germline mutation was identified in 448 (49\%) of them. The mutation detection rate was $75 \%$ in patients with typical FAP, $14 \%$ in patients with attenuated FAP and 33\% in the group of patients in whom the number of adenomas was not known.

The family history was known in 563 of the 917 index patients including 505 familial cases (90\%) and 58 cases with an apparently de novo mutation (10\%). The mutation detection rate was $62 \%$ in the 563 families with known family history, and $25 \%$ in the cases with unknown family history.

\section{Frequency of de novo mutations}

A germline mutation was detected in 52 of the 58 patients with a suspected de novo mutation (90\%) (Figure 1), including three patients with large, cytogenetically detectable deletions (partial loss of 5q). In 38 of these families, the mutation detected in the offspring was excluded in blood samples of both parents by applying direct sequencing of the fragment harbouring the mutation. The $5 \mathrm{bp}$ deletion at codon 1309 was over-represented in the group of patients with suspected de novo mutations $(17 / 58=29 \%)$ or proven de novo mutations $(17 / 38=45 \%)$ when compared to the familial cases $(26 / 505=5 \%)$. This difference was highly significant $(P<0.001$; Fisher's exact test).

\section{Parental origin of de novo mutations}

The parental origin of de novo mutations could be traced in 16 unrelated patients by haplotyping three- or twogeneration families (Figure 2 and Table 1). Paternity testing was performed by use of at least six polymorphic microsatellite markers from chromosomal regions $5 q$ and $17 p$ in all but three cases (families 4, 10 and 13) where no DNA of 


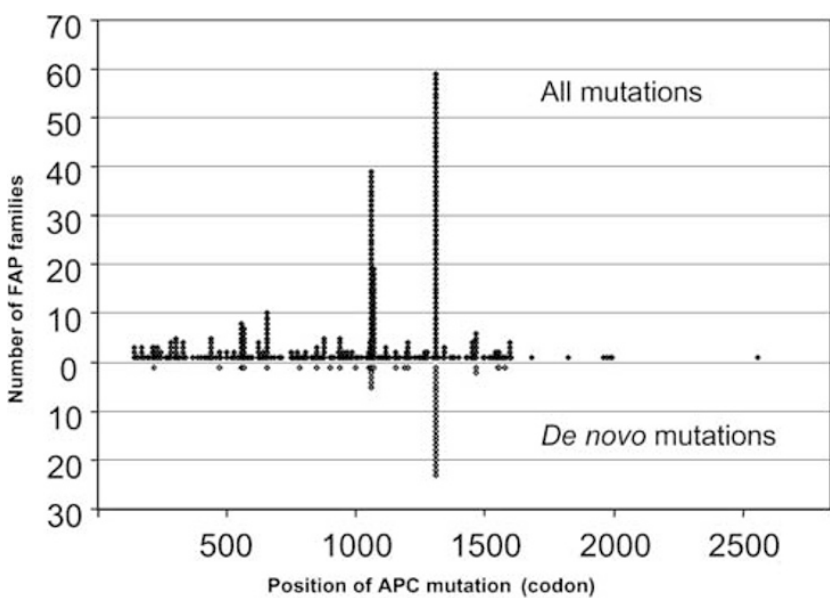

Figure 1 Distribution of germline mutations in the $A P C$ gene in 441 of 917 apparently unrelated FAP patients (without seven large deletions in 5q22) and distribution of de novo mutations in 49 unrelated patients (without the three chromosomal deletions).

the father was available. In family 10 , the paternal haplotype harbouring the mutation was deduced from analysis of a healthy, mutation-negative sib of the index patient who possesses the same paternal haplotype. In family 4 , the mutation occurred on the maternal haplotype; thus, in this case paternity is of no relevance. In family 13 , the mutation is localised on the paternal haplotype. According to anamnestic information, the father (71 years) had no bowel problems up to this age; however, in this case no mutation analysis or paternity test was possible. Thus, this is the only case where the parental origin cannot definitely be proven.

Overall, four mutations were of maternal and 12 mutations of paternal origin (Figure 2). Mutations in the maternal germ line included the $5 \mathrm{bp}$ deletion at codon 1309 that was found two times, and two additional small deletions (a 2 bp deletion at codon 1186 and a single base pair deletion at codon 1548). Mutations in the paternal germ line included five single-base exchanges (R216X, R564X, S1194X, S1201X, IVS13 + 3A > G), four small deletions (two 5 bp deletions at codon 1061, a 5 bp deletion at codon 1309 and a 2 bp deletion at codon 1465) and three large chromosomal deletions. An increased paternal age has not been observed in either of the families: in the cases with paternal origin, the father's age at the time of conception was calculated to be 29 years on average (range 23-35 years).
Interestingly, cytogenetically detectable deletions around 5q22 occurred in the paternal germ line only. Single-base exchanges were also detected in the paternal germ line only. On the other hand, small deletions were equally distributed between the maternal and paternal germ line (4:4).

\section{Discussion}

Germline mutations in the APC gene have been reported in $30-85 \%$ of FAP families, depending on the patients examined and the methods used for mutation analysis. $^{4,5,7,16,17}$ In our sample, an overall mutation detection rate of $49 \%$ was found. The distribution of mutations is consistent with published data (Figure 1). The rate of new mutations in FAP has been estimated to be between 5 and $9 \times 10^{-6}$ mutations per gamete per generation. ${ }^{1}$ The proportion of de novo mutations is approximately 11$25 \%{ }^{1,12,18}$ In our sample, de novo mutations were likely in around $10 \%$ of the 563 index patients with known family history. The low number may be caused by an ascertainment bias: whereas large FAP families with many affected members are easily diagnosed and reported, patients with a de novo mutation may present themselves with gastrointestinal symptoms in the third to fifth decade of life. Therefore, the genetic nature of the disease might be overlooked in part of the cases. On the other hand, the number of isolated cases may be overestimated due to occasional difficulties in obtaining accurate family histories and undiscovered nonpaternity. ${ }^{19}$ Moreover, in some apparently sporadic cases, recessive inheritance of multiple colorectal adenomas due to germline mutations in the base-excision-repair gene MYH has been detected. ${ }^{20}$

\section{Frequency of the $5 \mathrm{bp}$ deletion at codon 1309}

In most of the FAP cohorts examined, the $5 \mathrm{bp}$ deletion at codon 1309 is the most common germline mutation. In our sample, it occurred in 59/917 patients (6\%). Interestingly, a varying frequency of the 1309 mutation in different countries has been reported (Table 2): a high proportion was detected in Japan, Singapore and South Africa (mixed populations in part), ${ }^{21-23}$ a moderate frequency in most European populations ${ }^{5,7,16,17}$ and no 1309 deletions were found in Australia and Spain. ${ }^{24,25}$ These observations raise the question of a nonuniform distribution of the 1309 deletion. A potential explanation could be a founder effect. However, this assumption

Figure 2 Haplotype analysis in the families with confirmed de novo point mutations in the APC gene. Only informative markers are presented. The haplotype on which the de novo mutation had occurred is marked with a black bar. (a) The four families with maternal origin of the APC de novo point mutation. (b) The nine pedigrees with paternal origin of de novo point mutations (paternal DNA in pedigree 13 not examined). (c) The three pedigrees with large cytogenetically detectable deletions (Family 16 previously published. ${ }^{43}$ ); in these three families, paternity testing was performed with six additional highly polymorphic microsatellite markers from chromosomal region $17 \mathrm{p} 11.2$. 
a

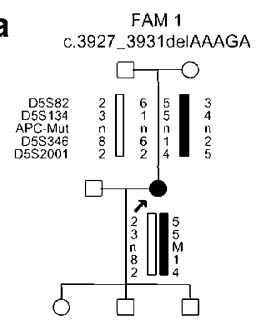

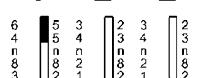

b

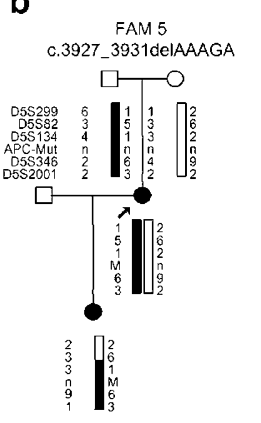

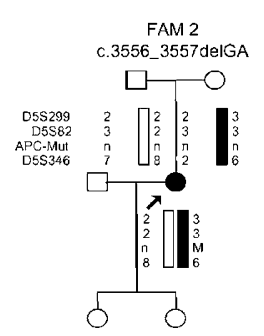

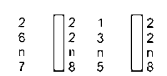

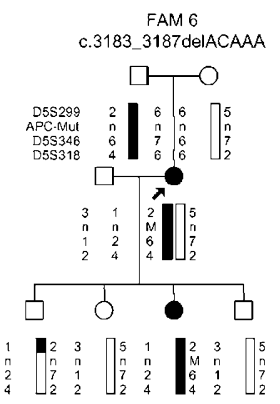

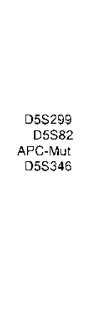

FAM 3

C. 4643 delA

$\square 0$

$\left[\begin{array}{l|ll}3 & 3 & 6 \\ 2 & 3 & 6 \\ n & 5 & 6 \\ 4 & 6 & 6 \\ 6 & 6 & 6\end{array}\right.$

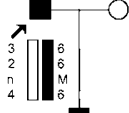

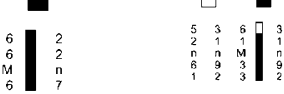

FAM 4

C.3927_3931deIAAAGA

区

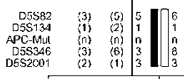

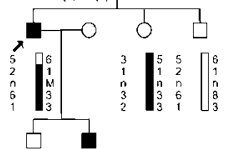

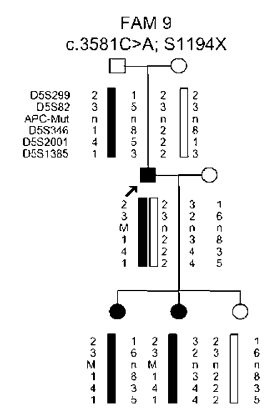
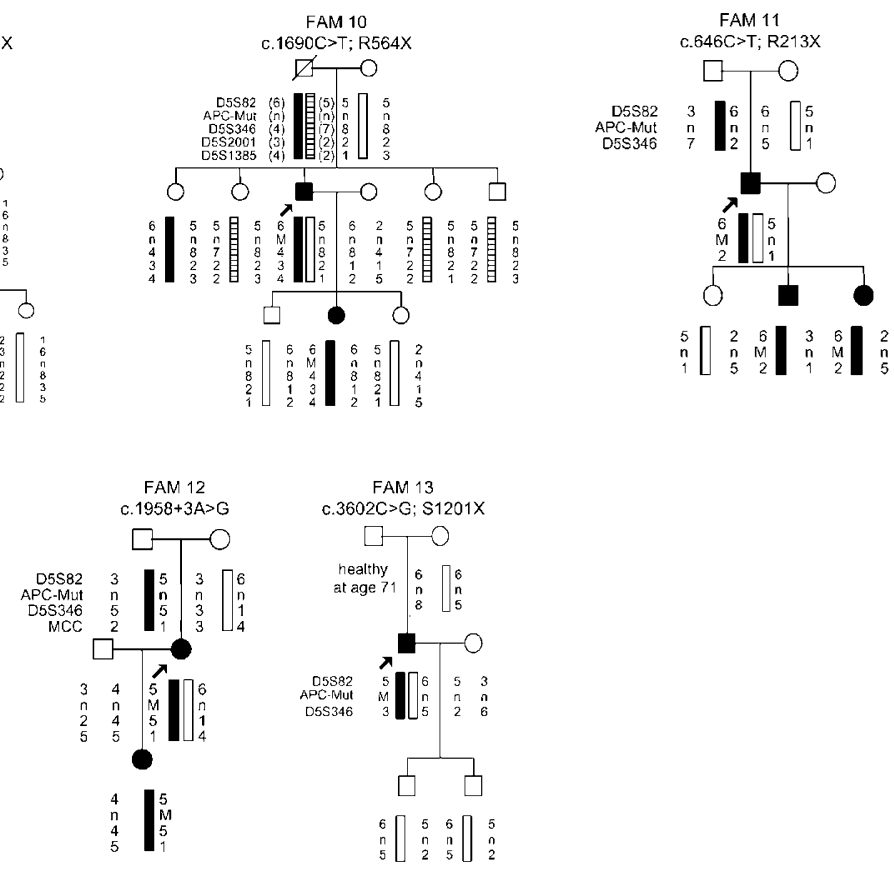

c
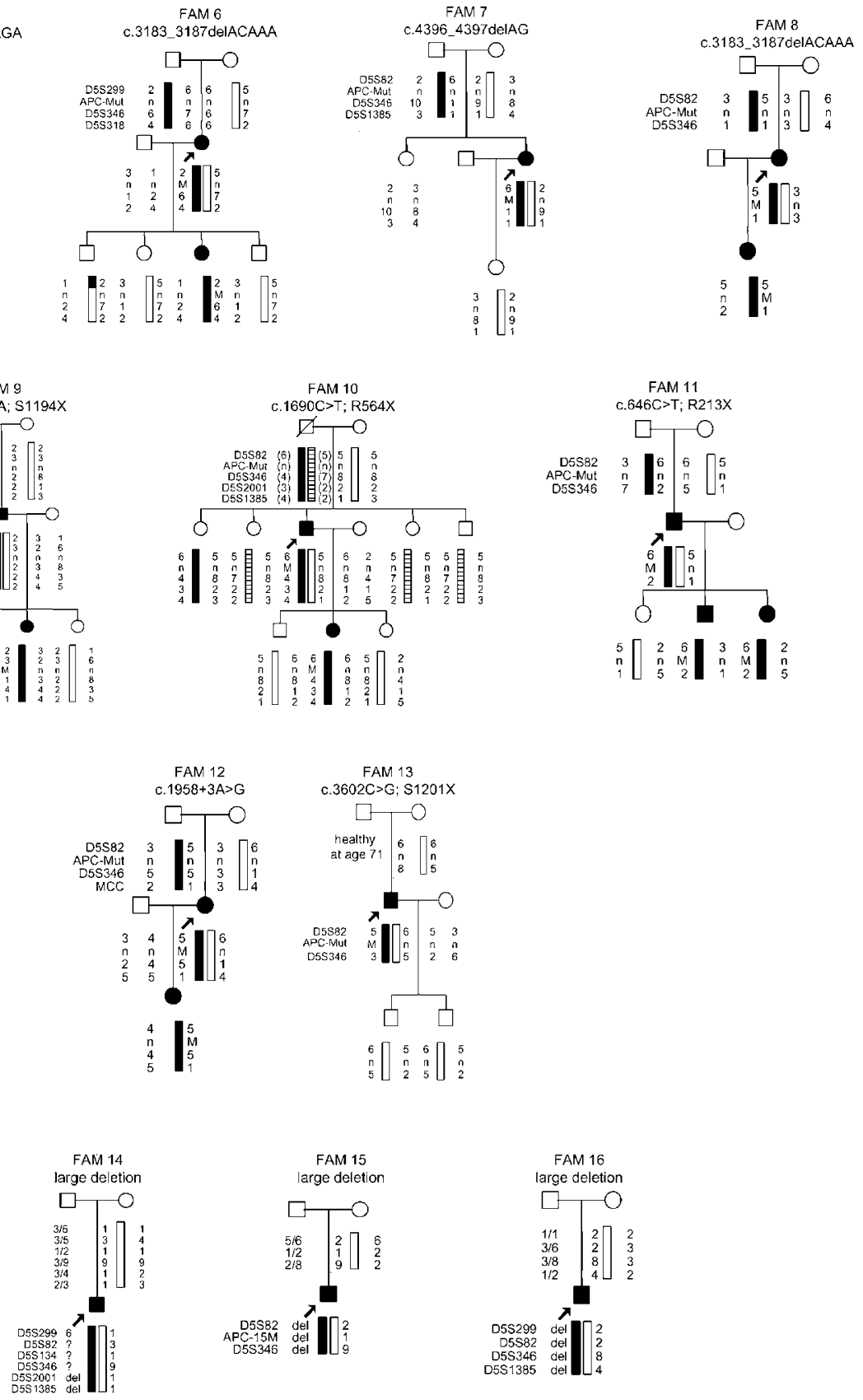

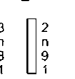

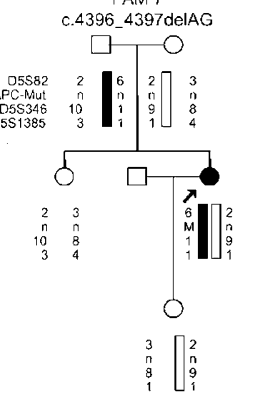


Table 1 Parental distribution of de novo mutations in the APC gene in 16 FAP patients

\begin{tabular}{|c|c|c|c|c|c|c|}
\hline \multicolumn{3}{|l|}{ Maternal origin } & \multicolumn{4}{|c|}{ Paternal origin } \\
\hline Exon & Codon & Mutation & & Exon & Codon & Mutation \\
\hline $\begin{array}{l}15 \mathrm{~F} \\
15 \mathrm{G} \\
15 \mathrm{I}\end{array}$ & $\begin{array}{l}1186 \\
1309 \\
1548\end{array}$ & $\begin{array}{l}\text { c. } 3556 \text { 3557delGA } \\
\text { c. } 3927 \text { 3931delAAAGA } \\
\text { c. } 4643 \text { delA }\end{array}$ & $\begin{array}{l}1 \times \\
1 \times \\
1 \times \\
2 \times \\
1 \times \\
1 \times \\
1 \times \\
1 \times \\
3 \times\end{array}$ & $\begin{array}{c}6 \\
13 \\
14 \\
15 \mathrm{E} \\
15 \mathrm{~F} \\
15 \mathrm{~F} \\
15 \mathrm{G} \\
15 \mathrm{H} \\
\text { Large }\end{array}$ & $\begin{array}{c}216 \\
564 \\
653 \\
1061 \\
1194 \\
1201 \\
1309 \\
1465 \\
\text { n (del5 }\end{array}$ & $\begin{array}{l}\text { c. } 646 \mathrm{C}>\mathrm{T} ; \mathrm{R} 216 \mathrm{X} \\
\text { c. } 1690 \mathrm{C}>\mathrm{T} ; \mathrm{R} 564 \mathrm{X} \\
\text { c. } 1958+3 \mathrm{~A}>\mathrm{G} \\
\text { c. } 3183 \_3187 \text { delACAAA } \\
\text { c. } 3581 \mathrm{C}>\mathrm{A} ; \text { S1194X } \\
\text { c. } 3602 \mathrm{C}>\mathrm{G} ; \text { S1201X } \\
\text { c. } 3927 \text { 3931delAAAGA } \\
\text { c. } 4393 \text { 4394delAG }\end{array}$ \\
\hline
\end{tabular}

Paternal DNA not examined (see text). ${ }^{\mathrm{b}}$ One patient previously published. ${ }^{44}$

Table 2 Frequency of the 5 bp deletion at codon 1309 in different studies

\begin{tabular}{lclr}
\hline Author & Patients & \multicolumn{1}{c}{ Country } & 1309 frequency (\%) \\
\hline Cao et $a l^{23}$ & 28 & Singapore, varying ethnicity & 29 \\
Grobbelaar et $a l^{27}$ & 22 & South Africa, varying ethnicity & 18 \\
Miyaki $e t a l^{21}$ & 119 & Japan & 14 \\
Friedl $e t a l^{7}$ & 680 & Germany & 6 \\
Wallis $e t a l^{5}$ & 205 & United Kingdom & 5 \\
Heinimann $e t a l^{16}$ & 50 & Switzerland & 4 \\
Giarola $e t a l^{17}$ & 66 & Italy & 3 \\
Scott $e t a l^{24}$ & 53 & Australia & 0 \\
Ruiz-Ponte $e t a l^{25}$ & 17 & Spain & 0 \\
\hline
\end{tabular}

appears to be unlikely: In our patients, the spectrum of de novo mutations shows a remarkable rate of the $5 \mathrm{bp}$ deletion at codon 1309 (29\% in patients with suspected and $45 \%$ in patients with proven de novo mutations) (Figure 1), being similar to previously published data $\left(28 \%{ }^{26}\right.$ and $\left.33 \%{ }^{12}\right)$. Both the high incidence of the 1309 deletion among de novo cases and the fact that the alteration was found to segregate with different haplotypes associated with the disease ${ }^{27,28}$ support the view that the sequence around codon 1309 is a hot spot of mutation.

The most convincing explanation for the difference in the frequency of the $5 \mathrm{bp}$ deletion at codon 1309 between de novo and familial cases is the severe form of disease caused by this mutation. This leads to a decreased reproductive fitness of affected persons - at least in previous generations - so that this condition primarily appears as spontaneous mutation. ${ }^{19}$ Since the reproductive fitness has been increased during recent decades through successful treatment, the frequency of the 1309 deletion in the FAP collective as a whole should increase as well until a new genetic equilibrium will be reached. ${ }^{1,26}$

The variation in the distribution of the 1309 deletion reported among different populations is presumably caused by an ascertainment bias. When only large families with many affected persons are considered for admission in FAP registries, the frequency of the $5 \mathrm{bp}$ deletion at codon 1309 will be reduced.

\section{Parental origin of APC mutations}

The parental origin of APC mutations in FAP has been scarcely examined so far. In some monogenic disorders caused by point mutations, such as achondroplasia, Apert syndrome or Crouzon syndrome, essentially all de novo mutations occur in the male germ line. ${ }^{10}$ A predominance of de novo mutations in the paternal germ line has been reported also for autosomal-dominant cancer syndromes such as multiple endocrine neoplasia (MEN 2A, 2B) ${ }^{29}$ and bilateral retinoblastoma. ${ }^{30}$

In some syndromes predominantly caused by single-base exchanges, the bias towards paternal origin has been strongly associated with increased paternal age at conception. ${ }^{31,32}$ Advanced paternal age is supposed to be responsible for the majority of new mutations in humans, ${ }^{11,33,34}$ some calculations assume a male/female ratio of the mutation rate of around $5 .{ }^{35}$ Since DNA replication errors are the primary source of germline mutations, one explanation for this phenomenon in diseases with underlying point mutations is the higher number of germline cell divisions in the life history of a sperm relative to that of an egg. This mechanism leads to an accumulation of single-base substitutions, which represent the most frequent class of mutations. The sex difference increases with the age at which the sperm is produced, possibly strengthened by a reduced fidelity of DNA replication, inefficiency of repair mechanisms, sperm selection or accumulation of mutagens with age. ${ }^{10,11}$ However, in a recent work, the 
age-related increase in mutation frequency in the FGFR3 gene in sperm DNA was found to be insufficient to explain the paternal age effect in achondroplasia. ${ }^{36}$

In contrast to base substitutions, which occur primarily in the male germ line, mutation types other than point mutations show different sex effects: In Charcot-MarieTooth disease type 1 A (CMT1A), approximately $90 \%$ of the $1.5-\mathrm{Mb}$ duplications arise during paternal spermatogenesis by meiotic unequal crossing-over between nonsister chromatids. ${ }^{37}$ On the other hand, in neurofibromatosis and Duchenne muscular dystrophy, point mutations originate in sperm predominantly, while large deletions are mostly of maternal origin. ${ }^{38-40}$ Thus, diseases in which a significant fraction of de novo mutations are not single-base substitutions should only have a small or no paternal age effect.

In the APC gene, the predominant mutation types are single-base substitutions as well as small deletions and insertions. In our sample, we identified the parental origin in 16 out of 52 FAP patients, in whom a germline mutation could be detected and a de novo mutation was suspected. The low number of patients in whom the parental origin could be traced (31\%) is mainly due to the inability of getting three-generation families, with problems in receiving blood samples from parents (no compliance, no more alive) or children (no children, or children under the age of 10 years in whom predictive testing is not recommended).

In all the parental DNA samples available for mutation or haplotype analysis, the mutation or large deletion identified in the de novo cases could not be detected. However, a possible mutational mosaicism in parental DNA cannot be excluded with the methods applied. Farrington and Dunlop $^{41}$ demonstrated mutational mosaicism in some apparently new APC gene mutation carriers by extensive studies on DNA samples of sporadic FAP patients and their parents. These authors emphasise the implications of a possible gonadal mosaicism for genetic counselling regarding the recurrence risk to siblings of sporadic FAP patients.

In four out of the 16 families, the mutations were of maternal and in 12 families of paternal origin (Figure 2). Thus, there is a moderate sex bias towards paternal origin. Interestingly, sex-related differences in parental origin of mutation types could be observed in our sample. In accordance with the observation that point mutations occur more frequently during spermatogenesis than oogenesis, the five de novo single-base exchanges we detected occurred only in the paternal germline. However, single-base substitutions are responsible for only about $25 \%$ of all APC germline mutations. The main mutation types are small deletions and insertions. With respect to these mutation types, we could not detect a sex bias in parental origin. Our results are similar to those of Ripa et al. ${ }^{12}$ They analysed the parental origin of 10 APC de novo mutations and found a 6:4 distribution in favour of maternal origin. The mutation spectrum in the sample of Ripa et al includes mainly small deletions except for one single-base exchange and one small insertion. Thus, with respect to the predominant mutation type in the $A P C$ gene, in both samples no differences in parental origin could be observed. Small deletions and insertions may result from other mechanisms than singlenucleotide exchanges and have no apparent sex bias.

We found that all cytogenetically detectable deletions occurred exclusively in the paternal germ line. A paternal preponderance is also known for other chromosomal deletions such as the partial loss of $18 \mathrm{q}$, $4 \mathrm{p}$ (Wolf-Hirschhorn syndrome) or $5 \mathrm{p}$ (cri-du-chat syndrome). ${ }^{10,11,42}$ The paternal origin of structural chromosome rearrangements detected in our sample is in accordance with observations in animal models: In drosophila and mice, the meiotic and postmeiotic stages of spermatogenesis (primary spermatocytes, spermatids) seem to be particularly sensitive to the induction of deletions and translocations, possibly due to the contractions during spermatid morphogenesis, whereas immature oocytes are known to have a lower overall sensitivity to mutation induction. ${ }^{11}$ In CMT1A, a testisspecific transposase or a greater protection from misalignment during oogenesis is suspected for the strong paternal predominance of duplications. ${ }^{37}$

Owing to the failure to detect a sex bias, Ripa et al assume a meiotic origin of APC germline mutations. Indeed, a lot of frameshift mutations in the APC gene occur in certain genomic sequences such as the codon 1309 or 1061 regions, which might predispose to mispairing events in meiosis. Thus, a meiotic origin seems to be plausible for small deletions and insertions. In contrast, single-base substitutions (and chromosomal alterations in part) seem to be mostly of paternal origin, as it would be expected from other monogenic diseases. Since small deletions and insertions are the predominant mutation types in FAP (Ripa et al found almost only frameshift mutations), a clear sex bias towards paternal origin could not be observed.

In conclusion, we found a moderate sex difference towards paternal origin of de novo mutations in FAP, caused by the predominance of single-base substitutions and large deletions in the paternal germ line. Nonetheless, these results are limited by the number of cases, which are too small for a valid statistical analysis. It will be interesting to examine what molecular mechanisms are responsible for the different frequencies of mutation types in the germ line of the two sexes.

\section{Acknowledgements}

We thank the patients and families, who participated in the study. The study was supported by the German Cancer Aid (Deutsche Krebshilfe e.V., Bonn, Project No. 70-2783-Fr 1).

\section{References}

1 Bisgaard ML, Fenger K, Bulow S, Niebuhr E, Mohr J: Familial adenomatous polyposis (FAP): frequency, penetrance, and mutation rate. Hum Mutat 1994; 3: 121-125. 
2 Bulow S, Holm NV, Hauge M: The incidence and prevalence of familial polyposis coli in Denmark. Scand J Soc Med 1986; 14: 67 74.

3 Bulow S: Familial adenomatous polyposis. Ann Med 1989; 21: 299-307.

4 van der Luijt RB, Khan PM, Vasen HF et al: Molecular analysis of the APC gene in 105 Dutch kindreds with familial adenomatous polyposis: 67 germline mutations identified by DGGE, PTT, and southern analysis. Hum Mutat 1997; 9: 7-16.

5 Wallis YL, Morton DG, McKeown CM, Macdonald F: Molecular analysis of the APC gene in 205 families: extended genotypephenotype correlations in FAP and evidence for the role of APC amino acid changes in colorectal cancer predisposition. $J$ Med Genet 1999; 36: 14-20.

6 Nagase H, Miyoshi Y, Horii A et al: Screening for germ-line mutations in familial adenomatous polyposis patients: 61 new patients and a summary of 150 unrelated patients. Hum Mutat 1992; 1: 467-473.

7 Friedl W, Caspari R, Sengteller M et al: Can APC mutation analysis contribute to therapeutic decisions in familial adenomatous polyposis? Experience from 680 FAP families. Gut 2001; 48: $515-521$

8 Nagase H, Miyoshi Y, Horii A et al: Correlation between the location of germ-line mutations in the APC gene and the number of colorectal polyps in familial adenomatous polyposis patients. Cancer Res 1992; 52: 4055-4057.

9 Caspari R, Friedl W, Mandl M et al: Familial adenomatous polyposis: mutation at codon 1309 and early onset of colon cancer. Lancet 1994; 343: 629-632.

10 Crow JF: The origins, patterns and implications of human spontaneous mutation. Nat Rev Genet 2000; 1: 40-47.

11 Chandley AC: On the parental origin of de novo mutation in man. J Med Genet 1991; 28: 217-223.

12 Ripa R, Bisgaard ML, Bulow S, Nielsen FC: De novo mutations in familial adenomatous polyposis (FAP). Eur J Hum Genet 2002; 10: 887-888.

13 Miller SA, Dykes DD, Polesky HF: A simple salting out procedure for extracting DNA from human nucleated cells. Nucleic Acids Res 1988; 16: 1215

14 Mandl M, Paffenholz R, Friedl W, Caspari R, Sengteller M, Propping P: Frequency of common and novel inactivating APC mutations in 202 families with familial adenomatous polyposis. Hum Mol Genet 1994; 3: 181-184.

15 van der Luijt $\mathrm{R}$, Khan PM, Vasen $\mathrm{H}$ et al: Rapid detection of translation-terminating mutations at the adenomatous polyposis coli (APC) gene by direct protein truncation test. Genomics 1994; 20: $1-4$.

16 Heinimann $\mathrm{K}$, Mullhaupt $\mathrm{B}$, Weber $\mathrm{W}$ et al: Phenotypic differences in familial adenomatous polyposis based on APC gene mutation status. Gut 1998; 43: 675-679.

17 Giarola M, Stagi L, Presciuttini S et al: Screening for mutations of the APC gene in 66 Italian familial adenomatous polyposis patients: evidence for phenotypic differences in cases with and without identified mutation. Hum Mutat 1999; 13: 116-123.

18 Rustin RB, Jagelman DG, McGannon E, Fazio VW, Lavery IC, Weakley FL: Spontaneous mutation in familial adenomatous polyposis. Dis Colon Rectum 1990; 33: 52-55.

19 Rees M, Leigh SE, Delhanty JD, Bowles L, Talbot IC: Molecular genetic evidence for the delineation of a more severe form of familial adenomatous polyposis which results from fresh mutation. Ann Hum Genet 1993; 57 (Part 2): 97-104.

20 Sieber OM, Lipton L, Crabtree $\mathrm{M}$ et al: Multiple colorectal adenomas, classic adenomatous polyposis, and germ-line mutations in MYH. N Engl J Med 2003; 348: 791-799.

21 Miyaki M, Konishi M, Kikuchi-Yanoshita R et al: Characteristics of somatic mutation of the adenomatous polyposis coli gene in colorectal tumors. Cancer Res 1994; 54: 3011-3020.

22 Grobbelaar JJ, Oosthuizen CJ, Kotze MJ: Screening South African familial adenomatous polyposis families for the five-nucleotide deletion at codon 1309 of the APC gene. Mol Cell Probes 1995; 9: $49-51$.

23 Cao X, Eu KW, Seow-Choen F, Zao Y, Cheah PY: APC mutation and phenotypic spectrum of Singapore familial adenomatous polyposis patients. Eur J Hum Genet 2000; 8: 42-48.

24 Scott RJ, Meldrum C, Crooks R et al: Familial adenomatous polyposis: more evidence for disease diversity and genetic heterogeneity. Gut 2001; 48: 508-514.

25 Ruiz-Ponte C, Vega A, Carracedo A, Barros F: Mutation analysis of the adenomatous polyposis coli (APC) gene in northwest Spanish patients with familial adenomatous polyposis (FAP) and sporadic colorectal cancer. Hum Mutat 2001; 18: 355.

26 Gayther SA, Wells D, SenGupta SB et al: Regionally clustered APC mutations are associated with a severe phenotype and occur at a high frequency in new mutation cases of adenomatous polyposis coli. Hum Mol Genet 1994; 3: 53-56.

27 Grobbelaar JJ, Oosthuizen CJ, Madden MV, Bailey SE, Retief AE, Kotze MJ: The use of DNA markers in the pre-clinical diagnosis of familial adenomatous polyposis in families in South Africa. $S$ Afr Med J 1995; 85: 269-271.

28 Cottrell S, Bicknell D, Kaklamanis L, Bodmer WF: Molecular analysis of APC mutations in familial adenomatous polyposis and sporadic colon carcinomas. Lancet 1992; 340: 626-630.

29 Carlson KM, Bracamontes J, Jackson CE et al: Parent-of-origin effects in multiple endocrine neoplasia type 2B. Am J Hum Genet 1994; 55: 1076-1082.

30 Kato MV, Ishizaki K, Shimizu T et al: Parental origin of germ-line and somatic mutations in the retinoblastoma gene. Hum Genet 1994; 94: 31-38.

31 Moloney DM, Slaney SF, Oldridge $M$ et al: Exclusive paternal origin of new mutations in Apert syndrome. Nat Genet 1996; 13: $48-53$.

32 Wilkin DJ, Szabo JK, Cameron R et al: Mutations in fibroblast growth-factor receptor 3 in sporadic cases of achondroplasia occur exclusively on the paternally derived chromosome. Am J Hum Genet 1998; 63: 711-716.

33 Malaspina D: Paternal factors and schizophrenia risk: de novo mutations and imprinting. Schizophr Bull 2001; 27: 379-393.

34 Penrose LS: Parental age and mutation. Lancet 1955; 269: $312-313$.

35 Makova KD, Li WH: Strong male-driven evolution of DNA sequences in humans and apes. Nature 2002; 416: 624-626.

36 Tiemann-Boege I, Navidi W, Grewal R et al: The observed human sperm mutation frequency cannot explain the achondroplasia paternal age effect. Proc Natl Acad Sci USA 2002; 99: $14952-14957$.

37 Bort S, Martinez F, Palau F: Prevalence and parental origin of de novo $1.5-\mathrm{Mb}$ duplication in Charcot-Marie-Tooth disease type $1 \mathrm{~A}$. Am J Hum Genet 1997; 60: 230-233.

38 Ainsworth PJ, Chakraborty PK, Weksberg R: Example of somatic mosaicism in a series of de novo neurofibromatosis type 1 cases due to a maternally derived deletion. Hum Mutat 1997; 9: $452-457$.

39 Lazaro C, Gaona A, Ainsworth P et al: Sex differences in mutational rate and mutational mechanism in the NF1 gene in neurofibromatosis type 1 patients. Hum Genet 1996; 98: 696-699.

40 Grimm T, Meng G, Liechti-Gallati S, Bettecken T, Muller CR, Muller B: On the origin of deletions and point mutations in Duchenne muscular dystrophy: most deletions arise in oogenesis and most point mutations result from events in spermatogenesis. J Med Genet 1994; 31: 183-186.

41 Farrington SM, Dunlop MG: Mosaicism and sporadic familial adenomatous polyposis. Am J Hum Genet 1999; 64: 653-658.

42 Chamberlin J, Magenis RE: Parental origin of de novo chromosome rearrangements. Hum Genet 1980; 53: 343-347.

43 Raedle J, Friedl W, Engels H, Koenig R, Trojan J, Zeuzem S: A de novo deletion of chromosome $5 \mathrm{q}$ causing familial adenomatous polyposis, dysmorphic features, and mild mental retardation. Am J Gastroenterol 2001; 96: 3016-3020. 